\title{
PENSAMENTO CENTRADO DA MAIORIA NÔMICA EM FAHRENHEIT 451: CONCEITOS DE PIAGET E MOSCOVICI NA OBRA DE RAY BRADBURY
}

\author{
Mariana Costa Nascimento ${ }^{1}$ \\ Geiva Carolina Calsa ${ }^{2}$
}

Resumo: A impressão de livros proporcionou o avanço e quebra de fronteiras, em decorrência de sua circulação mundial advindas da expansão do comércio entre Europa e Ásia. Além disso, repercutiu em mudanças cognitivas, sociais e afetivas para os povos de todo o mundo. O impresso, desde a sua origem passou a ser o novo condutor de ideias. Devido a propagação de crenças e valores, os livros passaram a ser proibidos e queimados em vários países ditatoriais, visto que os impressos poderiam corromper a base social e moral da sociedade. Esse contexto pode ser observado na obra Fahrenheit 451 de Ray Bradbury. O enredo narra a história de uma cidade em que os livros eram proibidos e como consequência queimados pelos bombeiros que executavam exclusivamente esse ofício. Partindo dessa obra procurou-se convergir os escritos de Bradbury com os conceitos de Jean Piaget e Sergi Moscovici. Os resultados indicam que a articulação entre os autores foi possível, pois a obra Fahrenheit 451 aborda aspectos psicossociais, pertinentes ao desenvolvimento individual e a relação dos grupos sociais formados pelos personagens da literatura. Além disso, a obra problematiza o papel do professor em sala de aula, visto que ao selecionar determinado autor e consequentemente excluir outros, o docente está "queimando" os demais escritores.

Palavras-chave: Educação. Representações. Piaget. Moscovici.

\begin{abstract}
The book printing provided the breakthrough and break boundaries, due to its worldwide circulation arising from the expansion of trade between Europe and Asia. Besides to that, it reflected in cognitive, social and emotional changes for people around the world. The printed, since its beginning it has become the new conductor of ideas. Due to the spread of beliefs and values, the books began to be banned and burned in various dictatorial countries, since

\footnotetext{
${ }^{1}$ Mestranda em Educação na UEM. E-mail: marianacostadonascimento@gmail.com.

${ }^{2}$ Docente do Programa de Pós-Graduação em Educação/UEM. E-mail: gccalsa@hotmail.com.
} 
the printed books could corrupt the social and moral basis of society. This context can be found in in the novel 451 Fahrenheit by Ray Bradbury. The plot is about a city in which the books were banned and burned by the firemen which exclusively performed this job. From this work, we tried to converge the writings of Bradbury with the concepts of Jean Piaget and Sergi Moscovici. The results point out that the relationship between the authors was possible because the work 451 Fahrenheit tackles psychosocial aspects, relevant to individual development and the relationship of social groups formed by the characters of literature. Furthermore, the novel discusses the role of teachers in the classroom, as when selecting a particular author and thus excludes others; the teacher is "burning" the other writers.

Key-Words: Education. Representation. Piaget. Moscovici.

Os livros, desde a invenção da imprensa trouxeram mudanças cognitivas, sociais e afetivas para os povos de todo o mundo. De acordo com Izabel Cecchini (2014, p. 1), as técnicas de imprensa se desenvolveram na China, desde o século VIII. Essas técnicas passaram a ser utilizadas na Europa "[...] por volta do ano de 1430, quando Coster, na Holanda, iniciou a impressão de livros com a utilização de caracteres móveis de madeira, razão pela qual é considerado por muitos como o pai da imprensa". Pouco mais tarde, inventada por Johanner Gutemberg em 1455, a imprensa foi responsável por uma das maiores contribuições para o mundo moderno.

Tendo como objetivo a divulgação do conhecimento, a impressão de livros proporcionou o avanço e a quebra de fronteiras geográficas, em decorrência de sua circulação mundial decorrente da expansão do comércio entre Europa e Ásia. Patrícia de Bandeira Melo (2005, p. 3) destaca que o livro, desde sua origem, passou a ser o novo condutor de ideias. "Filósofos, intelectuais e poetas passaram a expressão seus pensamentos em livros, fazendo suas ideias circularem na sociedade de forma mediada". Desenvolvem-se "[...] as primeiras impressões sobre a humanidade: as gazetas, com informações úteis sobre atualidade; os pasquins, folhetos com notícias sobre desgraças alheias; e os libelos, folhas de caráter opinativo".

Revista Eletrônica Literatura e Autoritarismo: A opressão na ficcionalização da história - ISSN 1679-849X http://cascavel.ufsm.br/revistas/ojs-2.2.2/index.php/LA/index 
Como repercussão desses três tipos de impressos, no século XVII, se organiza a atividade do jornalismo. A propagação e difusão dos jornais no final do século XVII e início do XVIII preparam o campo para a constituição de um novo espaço público para debate. Em princípio, os escritos jornalísticos "[...] eram dedicados a assuntos literários e culturais, mas a temática foi se alargando para questões de interesse social e político" (MELO, 2005, p. 3).

De acordo com Melo (2005), a circulação de impressos, por meio de livros e jornais, proporcionou mudanças político-sociais, como a Revolução Francesa e a ascensão da burguesia. Segundo Jorge Pedro Sousa (2003), seu crescente sucesso foi decorrente do aprimoramento das técnicas de tipografia cujo aumento das tiragens acabou por incentivar o gosto pela leitura e a curiosidade por assuntos diversos. Enquanto, a imprensa ganha força em países europeus, no Brasil, a produção literária foi permitida apenas no século XIX com a chegada da Imprensa Real trazida pela família real portuguesa (CECCHINI, 2014, p. 1)

$\mathrm{Na}$ Europa desde a Idade Média a censura de livros esteve relacionada à Igreja e ao Estado. No medievo, pessoas e documentos escritos que apresentavam ideias contrárias ao clero eram queimados em praça pública. Mais tarde, ainda, no século XX, continuamos assistindo a incineração de livros por dirigentes dos Estados, por perturbarem a ordem pública. Sobre esses fatos, Freud comentava com ironia "que progressos estamos fazendo? $\mathrm{Na}$ Idade média, teriam queimado a mim, hoje em dia, eles se contentam em queimar meus livros" (BRADBURY, 2012, p. 11).

Historicamente a prática de queima de livros está relacionada a guerras e regimes ditatoriais. Na Alemanha, em 1933, Joseph Goebbels, ministro da Propaganda e do Esclarecimento Popular, deu início a submissão de culturas não-germânicas, "processo pelo qual as artes foram moldadas para atender os objetivos nazistas" (USHMM, 2014, p. 1). Nas praças públicas de Berlim, com a presença de bombeiros e autoridades, os livros que desviavam dos ideais nazistas eram queimados.

Outro exemplo é o da China, onde durante a Revolução Cultural Chinesa (1966-1976) pessoas, livros e impressos que manifestavam ideias contrárias a Mao Tsé-Tung também forma condenados. Ao se sentir insatisfeito com os rumos do sistema comunista, Mao em uma reunião do Comitê Central do |46| Revista Eletrônica Literatura e Autoritarismo, no 25 - janeiro a junho de 2015 - ISSN 1679-849X http://cascavel.ufsm.br/revistas/ojs-2.2.2/index.php/LA/index 
Partido Comunista Chinês (PCC), em agosto de 1966, lançou a Revolução Cultural com a queima de todos os impressos e objetos que lembrassem a cultura burguesa ocidental. Partindo dos escritos de Kenneth Lieberthal (2012), Vinicius Cabral (2012) afirma que eram objetivos de Mao "corrigir o rumo das políticas do PCC; substituir seus sucessores por líderes mais afinados com o que pensava; assegurar uma experiência revolucionária à juventude chinesa; e tornar menos elitistas os sistemas educacional, cultural e de saúde" (CABRAL, 2014, p. 1). Para isso Mao mobilizou a juventude da China, que ficou conhecida como Guarda Vermelha. Chegando a ter quase 11 milhões de integrantes cujo intuito era o de destruir os velhos costumes da China, vandalizando monumentos históricos e perseguindo professores e intelectuais contrários ao PCC.

O romance Balzac e a Costureirinha Chinesa, editado em filme nos anos 2000 por Dai Sijie, ilustra esse momento histórico ao relatar a história de dois jovens Luo e Ma, que são encaminhados para o campo de reeducação (espaço que era destinado para aprendizagem dos novos princípios postulados por Mao Tsé-Tung). Ambos conhecem a costureirinha (Zhou Xun) que revela a eles um tesouro escondido e proibido - livros de Flaubert, Tolstói, Victor Hugo e Balzac.

No Brasil, a censura de livros também esteve relacionada a regimes ditatoriais como o regime militar de 1964 a 1985. Livros, revistas, jornais, peças teatrais publicadas, eram encaminhadas ao Departamento de Censura de Diversões Públicas (DCDP) que, nesse período, proibiu a divulgação de cerca de 490 livros, sendo 140 de autores nacionais. A lei 1077, 26 de janeiro de 1970 anunciava a censura direcionada aos livros que, de acordo com seu texto, poderiam destruir a base moral da sociedade. Em resposta a essa investida legal "[...] escritores, editores, intelectuais, artistas, cientistas, professores começaram a mobilizar-se para resistir e protestar contra os desmandos e arbítrios de um regime autoritário". No decorrer desse movimento um manifesto contra a censura assinado por mais de mil intelectuais brasileiros foi "[...] entregue ao ministro da Justiça em Brasília, em 25 de janeiro de 1977 (REIMÃO, 2014, p. 77).

Ações políticas de grupos sociais em prol de seus interesses e contrários à hegemonia fazem parte da história da humanidade e podem ser 
pensadas e discutidas a partir de perspectivas diversas, entre elas as que abordam os conceitos sobre maioria e minoria social. Maioria social refere-se "a qualquer grupo de pessoas que controle a maior parte de recursos econômicos, de status de poder, estabelecendo, assim, relações injustas com as minorias sociais". Minoria social refere-se a grupos que "[...] possuem traços cultuais, físicos [econômicos, políticos e religiosos] específicos que são desvalorizados e não inseridos na cultura da maioria, gerando um processo de exclusão e discriminação" (ROSO et al, 2002, p. 77).

Na obra de Serge Moscovici (2011, p. 83-84), ambos os grupos sociais podem ser divididos em nômicos e anômicos. Enquanto os grupos nômicos são normativos, organizados e engajados em movimentos políticos, os grupos anômicos não apresentam organização e consistência em suas ações que são dispersas. Por essa razão "só a minoria [nômica] pode exercer influência" social, visto que "oferecem algo novo (informações, argumentos, estilos, etc.) ao grupo, apresentam uma perspectiva diferente e, por isso, provocam um conflito que pode levar um grupo a mudar".

Supomos que essas duas formas de ações políticas podem ser interpretadas também levando em conta os conceitos de centração e descentração formulados por Jean Piaget (2010). Esses conceitos referem-se aos processos de interação do indivíduo com o outro enquanto aprende/apreende a realidade. Assim, aplicando-as às interações entre grupos sociais em luta consideramos que a censura aos posicionamentos divergentes pode ser interpretada como um pensamento predominantemente centrado em uma única compreensão da sociedade, enquanto as ações dos grupos antagônicos podem ser interpretadas como predominantemente descentradas por se apresentarem mais abertas a outras e diferentes leituras de mundo.

Segundo Marques (2005, p.81) "[...] embora tenhamos nos acostumado a relacionar o egocentrismo à criança pequena, é grande a preocupação de Piaget com o egocentrismo em todas as idades". Pensamento centrado e descentrado convivem em todos os momentos da vida humana na qual o primeiro constitui-se um dos principais entraves para a cooperação e socialização dos indivíduos. A autora comenta que grande parte dos problemas nas relações humanas é decorrente da "[...] incapacidade de um povo colocar-se no ponto de vista de 
outros povos". Dessa maneira, evidencia-se não mais um egocentrismo individual - centração -, mas o sociocentrismo.

Com base nos conceitos apresentados - centração e descentração, minoria e maioria nômica/anômica - nos perguntamos: É possível compreender as lutas entre grupos sociais a partir desses conceitos? Hipóteses favoráveis a essa questão nos fizerem produzir este ensaio cujo objetivo é o de apresentar a fecundidade e a convergência entre os conceitos apresentados de uma perspectiva psicossocial das interações entre grupos sociais. Para apresentar nossas considerações optamos pela análise de Fahrenheit 451, um conto de Ray Bradbury, publicado originalmente em 1953 e adaptado para o cinema em 1966 com o mesmo título do livro.

Nesta obra, ao descrever uma distopia social o autor discute as transformações culturais e morais que poderiam ser geradas pelo uso da televisão, mídia em ascensão no início da segunda metade do século XX. Entre essas transformações, Bradbury destaca a possibilidade de abandono da leitura, em particular, de obras literárias. Em sua distopia os livros representam o pensamento divergente e catalisador de movimentos políticos antagônicas ao status quo como veremos a seguir.

Sobre a obra Fahrenheit 451: considerações gerais

O enredo da Bradbury se passa em uma cidade fictícia chamada Fahrenheit 451, situada nos Estados Unidos. A cidade não se destaca por sua paisagem ou aparatos tecnológicos, mas por diferença marcante - as casas de Fahrenheit 451 são a prova de combustão. É esse o motivo pelo qual os bombeiros desempenham uma função diferente da que conhecemos: "[...] em lugar de apagar incêndios, sua tarefa é atear fogo". Os bombeiros "são agentes de higiene pública que queimam livros para evitar que suas quimeras perturbem 0 sono dos cidadãos honestos, cujas inquietações são cotidianamente sufocadas [...] pela onipresença da televisão (BRADBURY, 2012, p. 12).

Fahrenheit 451 (equivalente a aproximadamente 230 graus Celsius) se refere a temperatura na qual o papel queima e desmancha-se. $\mathrm{Na}$ obra, o 
protagonista Guy Montag é um bombeiro que segue rigorosamente o oficio de queimar as casas de proprietários que detém pelo menos um livro escondido. Acompanhado de Beatty (chefe dos bombeiros), dos amigos de serviço, Stroneman e Back, e com auxílio do mecânico, o bombeiro Montag executa seu trabalho todas as noites, a partir de denúncias recebidas.

Montag é casado com Mildred que dedica boa parte do seu tempo assistindo aos programas apresentados no circuito televisivo cuja tela substituem as paredes das casas da cidade. Ao conhecer sua vizinha, Clarice McClellan, Montag é levado a reconsiderar suas ideias e estilo de vida, a partir dos questionamentos da jovem de 16 anos.

No trabalho, enquanto revistava a casa repleta de livros de uma senhora para depois incendiá-la, Montag acidentalmente lê a linha de um de seus livros que dizia "O tempo adormeceu sobre o sol da tarde" (BRADBURY, 2012, p. 57). Esse trecho o incita a roubar o livro em princípio por pura curiosidade e, mais tarde, dá-se conta de vários. A senhora se recusa a deixar a casa e prefere queimar-se junto com seus livros, agonizando na combustão. Esse fato perturba Montag que passa a se perguntar porque alguém cometeria suicídio por causa de livros que, ao menos para ele, eram inúteis. Esse suicídio e a morte obscura e suspeita de sua jovem amiga Clarice, aumentam suas perturbações e o levam a procurar pessoas que lêem livros. É nessa busca que Montag conhece Faber, professor aposentado, que Ihe explica a importância dos livros para a humanidade - entrar em contato com pensamentos diferentes e divergentes. Ele entrega ao bombeiro uma escuta por meio da qual poderiam comunicar-se a longa distância.

Montag é denunciado por sua mulher sobre os livros que esconde em sua casa. O chefe dos bombeiros leva-o a casa para que ele mesmo ateie fogo. $O$ bombeiro queima os livros escondidos em sua casa, mas também, em fúria, os televisores. Ao descobrir a escuta, seu chefe ameaça Montag, que acaba por atear-lhe fogo. Ele foge e começa a ser perseguido pelas autoridades e por um cão policial mecânico. A perseguição é transmitida ao vivo pela televisão que torna-a um espetáculo assistido por milhares de pessoas.

Ao fugir encontra um grupo de refugiados que explicam a técnica que criaram para salvar os livros. Cada refugiado memoriza um livro, conservando $|50|$ Revista Eletrônica Literatura e Autoritarismo, oㅡ 25 - janeiro a junho de 2015 - ISSN 1679-849X http://cascavel.ufsm.br/revistas/ojs-2.2.2/index.php/LA/index 
todo seu conteúdo, que é transmitido de geração em geração com a esperanças de que chegue o momento em que os livros não sejam mais proibidos. Além dessa estratégia o grupo de leitores organiza movimentos militarizados de resistência ao poder hegemônico em busca de seu enfraquecimento.

A seguir as falas dos personagens de Fahrenheit 451 são discutidos levando em conta os conceitos selecionados das obras de Piaget (1987; 1994; 2010) e Moscovici (2011; 2012) minoria e maioria nômica e anômica e centração e descentração.

\section{Fahrenheit 451: uma leitura psicossocial da obra}

Fahrenheit 451 nos faz refletir sobre as repercussões da proibição dos livros em uma cidade fictícia dos Estados Unidos, tais como a dificuldade em se colocar no lugar do outro, o medo, a tentativa de fuga, a curiosidade, a resistência e o pensamento divergente. Logo no início da obra, observamos a relutância de Montag em aceitar as colocações de Clarice. O bombeiro "fechado" em seus ideais, parece não procurar entender o pensamento da garota, que questiona e apresenta posições divergentes das hegemônicas na cidade. É nesse sentido que inferimos que as respostas abaixo, de Montag a Clarice, sugerem convergência com o conceito de centração presente na obra de Jean Piaget (2010):

- Você nunca lê nenhum dos livros que queima?

Ele riu

- Isso é contra lei!

- Ah, é claro.

- É um trabalho ótimo. Segunda-feira, Millay; quarta-feira, Whitman, sexta-feira, Faulkner. Reduza os livros às cinzas e, depois queime as cinzas. Este é nosso slogan oficial.

Caminharam ainda mais um pouco e a garota disse:

- É verdade que antigamente os bombeiros apagavam incêndios em vez de começa-los?

- Não. As casas sempre foram à prova de fogo, pode acreditar no que eu digo. (p. 26).

A centração é recorrente nos personagens da obra. Em outro excerto do livro, durante a conversa entre Montag e Beatty, também observamos o 
pensamento centrado do chefe dos bombeiros nos princípios do Estado e obediência completa às suas normas. Entretanto, no decorrer do diálogo com Beatty, percebemos um novo movimento de Montag. Neste movimento, suas condutas parecem direcionar-se a um pensamento descentrado, pois procura colocar-se no lugar dos cidadãos que foram agredidas com a destruição de seus livros.

Montag, olhou para as cartas em suas mãos.

- Eu ... estava pensando. Sobre o fogo da semana passada. Sobre o homem cuja biblioteca nos eliminamos. O que aconteceu com ele?

- Eles o levaram gritando para o hospício.

- Ele não era demente.

Beatty organizou calmamente as suas cartas.

- Todo homem é demente quando pensa que pode enganar o governo e a nós.

- Eu só estava imaginando - disse Montag - como seria. Quero dizer, se os bombeiros queimassem as nossas casas e os nossos livros.

- Não temos nenhum livro (p. 54).

A descentração de Montag segue com o desenrolar da obra. Podemos visualizá-la novamente quando o bombeiro procura colocar-se no lugar dos autores de livros. Enquanto isso, os demais personagens continuam resistentes a um pensamento divergente dos dominantes. Mais um exemplo refere-se aos dizeres da esposa de Montag nos quais observamos que assim como Beatty, a senhora Mildred manifesta centração em sua forma de pensar:

- Ontem a noite eu pensei em todo querosene que usei nos últimos dez anos. E pensei nos livros. E pela primeira vez percebi que havia um homem por trás de cada um dos livros. Um homem teve de concebê-los. Um home teve de gastar muito tempo para coloca-los no papel. $E$ isso nunca me havia passado pela cabeça.

Montag saiu da cama.

- Às vezes pode levar uma vida inteira para um homem colocar seus pensamentos no papel, depois de observar o mundo e a vida, e aí eu chego e, em dois minutos, bum! Está tudo terminado.

- Me deixe em paz - disse Mildred - Eu não fiz nada.

- Deixar você em paz? Tudo bem, mas como posso ficar em paz? Não precisamos que nos deixem em paz. Precisamos realmente ser incomodados de vez em quando. Quanto tempo faz que você não é realmente incomodada? Por alguma coisa importante, por alguma coisa real? (p. 74). 
Observamos no excerto acima que as problematizações de Montag não geram em Mildred a tentativa de colocar-se no lugar do marido, objetivando entender as aflições de seu ofício como bombeiro. A fuga de Mildred da conversa e dizeres, como "Me deixe em paz", denotam que a mulher não deseja escutar outro ponto de vista sobre a profissão bombeiro, preferindo ficar centrada em sua própria ideia sobre o ofício.

Além dos conceitos piagetianos citados, a obra de Bradbury também nos remete aos conceitos de maioria e minoria anômica e nômica de Serge Moscovici. No diálogo abaixo entre Montag e Beatty, inferimos que os bombeiros formam a chamada maioria nômica, pois estão assegurados perante a lei e o Estado. As cinco regras descritas por Beatty, demonstram que os bombeiros constituem-se como grupo consistente na execução de sua função: atear fogo nos livros.

- Foi sempre assim? O posto de bombeiros, nosso trabalho? Bem, quer dizer, será que antigamente, houve um tempo ... [disse Montag]

- Houve um tempo!? - disse Beaty - Que conversa é essa? Idiota, pensou Montag, você acabará se traindo. No último fogo, num livro de contos de fadas, ele vira de relance uma única linha.

- O que eu quero dizer - disse ele -, é que antigamente, antes que as casas fossem totalmente à prova de fogo - de repente era como se uma voz muito mais jovem estivesse falando por ele; ele abriu a boca e era Clarice McClellan dizendo -, os bombeiros não combatiam os incêndios em lugar de inicia-los ou alimentá-los?

- Essa é boa - Stoneman e Black sacaram seus livros de regras que também continham histórias resumidas dos Bombeiros da América e os abriram onde Montag, ainda que já conhecesse de sobra, pôde ler:

Fundado em 1790 para queimar livros de influência inglesa nas colônias.

Primeiro bombeiro: Benjamin Franklin

1를 Regra: Atenda prontamente ao alarme.

2 ${ }^{a}$ Regra: Comece o fogo rapidamente

3를 Regra: Queime tudo.

4a Regra: Reporte-se imediatamente ao posto de bombeiros.

5" Regra: Fique sempre alerta a outros alarmes. 
As dúvidas de Montag sobre sua profissão foram despertadas a partir dos diálogos com sua vizinha Clarice que parece tê-lo deixado em desequilíbrio sobre suas ideias e valores. Moscovici (2011, p. 9) comenta que "o poder da minoria é influenciar e transformar a maioria mediante a um comportamento consistente que acaba criando conflito e dúvida entre os membros da maioria, conduzindo-os a examinar e re-avaliar sua própria postura cognitiva, e por conseguinte valorativa".

Consideramos pensar em Clarice como representante de uma minoria dissidente capaz de desequilibrar uma maioria nômica. Embora, no início, as condutas da personagem se aproximassem de uma minoria anômica, ao longo da obra percebemos que faz parte de um grupo organizado e articulado que busca manter os livros vivos, assim como influenciar outras pessoas nessa direção. Assim, consideramos que Clarice pertence a uma minoria nômica consistente e coerente capaz de problematizar e instigar o pensamento de Montag. Sua influência vai minando as certezas do bombeiro que passa a se sentir inseguro sobre suas ideias. Abrem-se dessa maneira as condições de influência da minoria nômica como nos indica Moscovici (2011, p. 30) "quando um grupo, um subgrupo ou indivíduo estão seguros de algo, não se pode utilizar a influência para induzi-los a modificar suas opiniões e seus julgamentos".

No final do enredo de Fahrenheit 451 conhecemos outros membros dessa minoria nômica, os refugiados que se mantém na floresta dos arredores da cidade. Esse grupo mantém seus objetivos em ação com coerência e precisão, como ilustra o excerto a seguir sobre um diálogo do líder dos refugiados, Ganger, com Montag:

[...] - Montag algum dia você gostaria de ler a República de Platão?

- Claro!

- Eu sou a Republica de Platão. Gostaria de ler Marco Aurélio?

O senhor Simmons é Marco Aurélio

- Como vai? - disse o sr. Simmons

[...]

- Não pode ser - disse Montag

- Mas é, replicou Ganger, sorrindo. - E também somos queimadores de livros. Lemos os livros e os queimamos, por medo que sejam encontrados. Não compensava micro filmálos; estávamos sempre viajando, não queríamos enterrar o 
filme para voltar mais tarde. Sempre havendo o risco de sermos descobertos. O melhor é guarda-los na cabeça, onde ninguém virá procurá-los. Somos todos fragmentos e obras de história, literatura e direito internacional (p. 185-186).

Por meio do diálogo constatamos que a memorização dos livros queimados pelo grupo constitui-se uma estratégia encontrada pelos refugiados para manter vivos os escritos. "Passaremos os livros adiante a nossos filhos, de boca em boa, e deixaremos nossos filhos, por sua vez, sirvam a outras pessoas". Esse processo é previsto até que a censura acabe. Os refugiados vêm a guerra crescente que o governo estabelece contra eles como uma esperança para provocar o desequilíbrio de mais pessoas da comunidade sobre os livros. Ou seja, a guerra poderia enfraquecer os ideais e valores de um maior contingente da maioria nômica em direção a revogação da leitura dos livros. A falta de segurança e a vulnerabilidade das pessoas poderia contribuir para a aceitação de outros pontos de vista sobre a leitura dos livros. Em outras palavras, poderia promover um movimento de descentração e autonomia moral desses indivíduos.

A manutenção das normas do Estado entre a maioria nômica descrita em Fahrenheit 451 é realizada por meio da propaganda, outro conceito desenvolvido por Moscovici (2012) para tratar sobre a influência social entre indivíduos e grupos sociais. A propaganda desempenha uma função reguladora em que cada grupo ou instituição busca impor a sua ideia através de estratégias de repetição e persuasão.

De outro lado, a minoria nômica, dos amantes e leitores de livros, parece comunicar-se com essa maioria por meio da estratégia de propagação de suas ideias, posicionamentos e valores por meio da qual transmite as informações divergentes. Contudo, diferentemente da propaganda, a estratégia de propagação de suas ideias possibilita ao receptor um maior espaço para formação de suas opiniões, favoráveis ou desfavoráveis, assim como dúvidas e questionamentos, como explica Moscovici (2012).

Com base nos conceitos de Moscovici e Piaget podemos afirmar que 0 pensamento centrado da maioria nômica da cidade de Fahrenheit 451 é comunicado ao conjunto social por meio do mecanismo de propaganda, 
enquanto o pensamento descentrado da minoria nômica é partilhado por meio da estratégia de propagação de suas ideias divergentes, possibilitando aos cidadãos abertura para a tomada de decisões por parte de cada um.

A organização de pessoas que lutam por ideias não hegemônicas, representada pela minoria nômica, demarca a resistência de grupos que buscam construir novos caminhos entre a maioria nômica e anômica. As estratégias de propaganda e propagação representam o esforço social e individual para a comunicação e circulação de ideias seja para sua imposição, seja para sua discussão e decisão.

\section{Considerações Finais}

A análise da obra de Bradbury nos traz as repercussões individuais e sociais a norma de incendiar livros em Fahrenheit 451 nas quais vislumbramos a convergência de conceitos de Jean Piaget e Serge Moscovici. No enredo de Bradbury, ao destruírem com o fogo os livros, os bombeiros acabavam também queimando opiniões, individualidades e pensamentos divergentes.

Os resultados encontrados indicam que a maior parte dos personagens da história apresentam características de um pensamento centrado, pois demonstram dificuldade em compreender e aceitar outros pontos de vista sobre a queima de livros. Fecham-se na ideia de que as obras devem ser destruídas pelos bombeiros e não aceitam pensamentos divergentes dos seus sobre o assunto. Concluímos que esses personagens constituem a maioria nômica. Trata-se de um grupo organizado e consistente assegurado pela lei e pelo Estado. De outro lado, os poucos personagens que manifestam pensamento descentrado fazem parte da minoria nômica. Refere-se ao grupo que luta em prol da permanência dos livros e que demonstram aceitação para repensar o ofício dos bombeiros e a destruição dos livros.

Para concluir, como educadoras, não podemos deixar de fazer uma analogia dos fatos retratados em Fahrenheit 451 com a instituição escolar. Nesta perspectiva, ao selecionar determinado autor ou teoria para abordar em sala de aula, o professor acaba também queimando os que deixaram de ser estudados e, as vezes, até citados. Tomaz Tadeu da Silva (2004) nos explica 
que a ação de escolher determinados autores e consequentemente "queimar" outros, está relacionado a ideia de que o currículo escolar envolve relações de poder inerentes ao processo de formação de identidades. A escola tem sido uma das instituições mais importantes na função social de comunicação e circulação de um pensamento predominantemente centrado e hegemônico (ALTHUSSER, 1985; 1999; BOURDIEU, 2004; 2008). Ao mesmo tempo, também destacam a propaganda como estratégia de comunicação desse pensamento regulador do status quo da sociedade.

Podemos, assim, concluir que vivemos Fahrenheit 451 em várias instituições sociais e muitas maneiras diferentes e, muitas vezes, não percebidas. Mesmo porque o embate entre pensamento centrado e descentrado, bem como os movimentos de resistência de minorias nômicas estão sempre presentes nos conjuntos sociais.

\section{REFERÊNCIAS}

ALTHUSSER, Louis. Aparelhos ideológicos do Estado (AIE). Rio de Janeiro: Graal, 1985, 127 p.

Sobre a reprodução. Petrópolis: Vozes, 1999, 294 p.

BOURDIEU, Pierre. O poder simbólico. Rio de Janeiro: Betrand Brasil, 2004, $311 \mathrm{p}$.

A reprodução. Petrópolis: Vozes, 2008, 276 p.

BRADBURY, Ray. Fahrenheit 451. São Paulo: Globo, 2012, 215 p.

BRAGA, Claudomilson; TUZZO, Simone Antoniaci. A tipologia das representações sociais e os atos comunicativos: o caso da reserva indígena raposa serra do sol. Revista Anhanguera, v.11, n.1, jan./dez.2010, p. 87-104.

CABRAL, Vinicius. A Revolução Chinesa. [S.I], Históriazine, 2012, Disponível em http://www.historiazine.com/2012/01/a-revolucao-chinesa.html. Acesso em 15 de dez.2014.

CASTRO, Paula. Notas para uma leitura da teoria de representações sociais em Sergi Moscovici. Análise Social, v.37, n. 164, 2002, p. 949-979

CECCHINI, Izabel. A invenção da imprensa. [S.I] 2014. Disponível em: http://www.casadomanuscrito.com.br/curio 07.htm. Acesso em 12 dez.2014 
MARQUES, Tânia Beatriz Iwaszko. Do Egocentrismo à Descentração: a docência no ensino superior. Tese (Doutorado) - Programa de Pós-Graduação em Educação, Universidade Federal do Rio Grande do Sul, Porto Alegre, 2005, $264 \mathrm{p}$.

MELO, Patrícia Bandeira de. Um passeio pela História da Imprensa: o espaço público dos

grunhidos ao ciberespaço. Comunicação e informação, v. 8, n. 1 p. 26 - 38, jan/ jun.

2005.

MONTANGERO, Jacques; NAVILLE-MAURICE, Danielle. Piaget ou a inteligência em evolução. Porto Alegre: Artmed, 1998, 242 p.

MOSCOVICI, Serge. Psicologia das minorias ativas. Petrópolis: Vozes, 2011, $287 \mathrm{p}$.

Vozes, 2012, $456 \mathrm{p}$

A Psicanálise, sua imagem e seu público. Petrópolis:

PIAGET, Jean. O nascimento da inteligência. Rio de Janeiro: Guanabara, 1987, 392 p.

O juízo moral na criança. São Paulo: Summus, 1994, 302 p.

Seis estudos de Psicologia. Rio de Janeiro: Forense

Universitária, 2010, 136 p.

REIMÃO, Sandra. Proíbo a circulação e publicação ... censura a livros na ditadura militar. Estudos Avançados, São Paulo, v. 28, n.80, jan./abr.2014

ROSO, Adriane et al. Cultura e ideologia: a mídia revelando estereótipos raciais de gênero.

Psicologia \& Sociedade, Porto Alegre, v.14, n. 2, p. 74-94, jul/dez 2002.

SIJIE, Dai. Balzac e a costureirinha chinesa. São Paulo: Alfaguara Brasil, 2007, $168 \mathrm{p.}$

SILVA, Cleânia de Sales. As representações sociais nos discursos midiáticos: novas questões para a educação. Caxambu, 28 Anped, 2005. GT.16 Educação e Comunicação. Disponível em: http://28reuniao.anped.org.br/. Acesso em 17 de dezembro de 2014.

SILVA, Tomaz Tadeu da Silva. Documentos de identidade: uma introdução das teorias do currículo. Belo Horizonte: Autêntica, 2004, 156 p.

SOUSA, Jorge Pedro. Elementos da Teoria e Pesquisa da Comunicação e dos Media. Porto, 2006, 823 p. 